\title{
Effect of continuous administration of low-medium flow oxygen for non-ventilated lung during one lung ventilation surgery on blood gas analysis and oxidative stress response in lung tissue of tumor patient\A randomized controlled trial
}

Tang-Jing Wu

Wuhan University Zhongnan Hospital

Jia Zhan

Wuhan University Zhongnan Hospital

Jian-Juan Ke

Wuhan University Zhongnan Hospital

Zong-Ze Zhang

Wuhan University Zhongnan Hospital

Yan-Lin Wang ( $\nabla$ wyl0342@sina.com )

Research article

Keywords: anesthesia, one lung ventilation, blood gas analysis, oxidative stress, lung tissue, adult

Posted Date: January 24th, 2020

DOl: https://doi.org/10.21203/rs.2.21458/v1

License: (c) (i) This work is licensed under a Creative Commons Attribution 4.0 International License.

Read Full License 


\section{Abstract}

Background: One-lung ventilation (OLV) induces hypoxia during the operation and oxidative stress to the non-ventilated lung (NVL) which may cause acute lung injury (ALI). Aims: We sought to find out whether continuous administration of low-medium flow oxygen for NVL during OLV can mitigate the oxidative stress in lung tissue of patient.

Methods: After local Ethics Committee approval and informed consent, we randomly allocated fifty-seven patients scheduled for elective pulmonary tumor resection. The F14 tube was placed at 2-3cm beyond the carina of trachea in the NVL at the time of the beginning of the OLV in group 0 , administrating continuously with oxygen. Blood samples were taken from radial artery and internal jugular vein simultaneously for blood gas analysis, immediately after induction of anesthesia (T 1 ), 30min (T 2 ), $1 \mathrm{~h}$ (T 3 ) and $2 \mathrm{~h}$ (T 4 ) after OLV. Lung tissue was taken $5 \mathrm{~cm}$ distant from the tumor for determination of superoxide dismutase(SOD) and malondialdehyde(MDA), and expression of heme oxygenase-1(HO-1) .

Result: Compared with group $\mathrm{C}$, the $\mathrm{PaO} 2$ was significantly increased at T 2-4 and the PaCO 2 was significantly decreased at T 2,3, the PvO 2 was significantly increased at T 2,3 and the PvCO 2 was significantly decreased at T 2-4, the lung concentration of MDA was significantly lower and the local expression level of $\mathrm{HO}-1$ in lung was significantly elevated in group $\mathrm{O} \otimes \mathrm{P}<0.05 \rrbracket$.

Conclusion: The administration of continuous low-medium flow oxygen for NVL during OLV has shown the effect of pulmonary protection. The possible mechanism is related with the inhibition of the oxidative stress response in lung tissue.

\section{Background}

One-lung ventilation (OLV) is usually performed to provide wide surgical area in thoracic surgeries[1]. Lots of studies implied that OLV can cause lung injury[2-4]. OLV is an important induced factor of acute lung injury (ALI), which is one of the major causes of death after thoracic surgery and the mortality is stable in $2-5 \%[5]$. During OLV, alveolar collapse occurs in the NVL then causing hypoxia, and hypoxic pulmonary vasoconstriction caused hypoperfusion in the NVL tissue[6]. The reoxygenation and the ischemiareperfusion injury also aggregate ALI.

Oxidative stress is an important factor of ALI during OLV, and it is found that oxidative stress plays an important role in the structure, function, and inflammatory response of the ALI model[7]. Misthos $\mathrm{P}$ et al stated that the degree of the amount of generated oxygen free radicals is associated with the duration of OLV, especially for patients with lung cancer[8]. After resuming two-lung ventilation (TLV), the reperfusion of the blood and reentry of oxygen to ischemic tissue cause sudden and significant increase in reactive oxygen species (ROS) production[9]. The total antioxidant status (TAS) of human body counteracts oxidative stress. Cheng YJ et al claimed that there is no significant decrease in the total antioxidant status after resuming TLV, which indicates adequate antioxidant capacity to counteract it, and they thought that severe oxidative injuries after OLV/TLV should be considered in patients without adequate 
antioxidative capacity, such as those with cancer and trauma[9]. Therefore, the new question of how to reduce the oxidative stress injury for patient with lung cancer during the surgery needs to be answered.

Continuous administration of low-medium flow oxygen for NVL during OLV provides adequate oxygen supply in the NVL and avoid the interference of the operation view. We wish to investigate the effect of continuous administration of low-medium flow oxygen for NVL during OLV on oxidative stress in lung tissue of patient, and to seek a new protective strategy for ALI.

\section{Methods}

\section{Study design and patient population}

This randomized, prospective double-blind study enrolled 60 patients from Jan, 2, 2017 to Mar, 17, 2017. All procedures performed in studies involving human participants were in accordance with the ethical standards of the Medical Ethics Committee of Zhongnan Hospital of Wuhan University (Clinical Trial Registry number, 2016020) and with the 1964 Helsinki declaration and its later amendments or comparable ethical standards.

\section{Criteria for inclusion and exclusion}

The patients were classified as physical status I or II according to the American Society of Anesthesiologists, ranged in age between 18 and 64 years old and were scheduled to undergo videoassisted thoracoscopic surgery requiring OLV. Each of them was randomly divided into two groups by random number table method: experimental group (Group 0, continued low-medium flow oxygen in NVL, $\mathrm{n}=28$ ), control group (Group $\mathrm{C}, \mathrm{n}=29$ ). The exclusion criteria included patients with the following conditions: Surgery for more than 4 hours $₫$ Need to stop single lung ventilation during surgery to restore dual lung ventilation to maintain oxygen saturation $>90 \% \bigotimes$ Patients have an immune diseaseखUpper respiratory tract infection $\bigotimes$ Preoperative pulmonary function tests measured values lower than the minimum required value of various lung resection preoperative pulmonary function test (FEV1 $<70 \%$ of

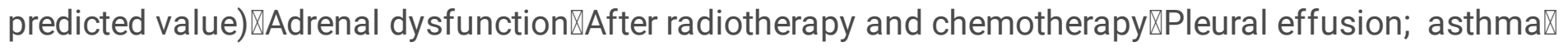
Oral hormonal therapy within three months before surgery.

\section{Preoperative preparations and anesthesia protocol}

The patients received no premedication. When the patients arrived in the operating room, they were monitored by pulse oximetry, electrocardiography (ECG), non-invasive blood pressure (NIBP). Using a catheter inserted into a peripheral vein, $6 \mathrm{ml} / \mathrm{kg}$ of crystalloid was injected into the patients. The patients were randomly assigned to groups 0 and $C$. After anesthesia was induced with sufentanil $0.2-0.3 \mathrm{ug} / \mathrm{kg}$, propofol $1-2 \mathrm{mg} / \mathrm{kg}$ and rocuronium bromide $0.6-1.0 \mathrm{mg} / \mathrm{kg}$, the patients were intubated with a nonoperation lateral double-lumen tube(DLT) (size F35 for women and size F37 for men) by experienced thoracic anesthesiologists involved in the study, and the correct position was confirmed using a fiberoptic bronchoscope (FOB). In the initial two-lung ventilation (TLV) and one-lung ventilation (OLV) period, the 
tidal volume $(\mathrm{Vt})$ was $4-5 \mathrm{ml} / \mathrm{kg}$, the respiratory rate was $12-15 \mathrm{bpm}$, the I/E ratio was $1: 2$, and the positive endexpiratory pressure (PEEP) was $5 \mathrm{cmH} 2 \mathrm{O}$. Anesthesia was maintained using propofol $4-10 \mathrm{mg} \cdot \mathrm{kg}^{-1} \cdot \mathrm{h}^{-1}$, remifentanil 1.5-120 ug $\mathrm{kg}^{-1} \cdot \mathrm{h}^{-1}$, cisatracurium 0.05-0.1 mg $\mathrm{kg}^{-1} \cdot \mathrm{h}^{-1}$, dexmedetomidine $0.2-0.7 \mathrm{ug} \cdot \mathrm{kg}^{-1} \cdot \mathrm{h}^{-1}$, and auxiliary inhalation sevoflurane $0.5 \%-1 \%$. The mean arterial blood pressures (MAP) and heart rates (HR) were $20 \%$ less than the baseline values. The patient was placed in a lateral decubitus position after right internal jugular central venous catheterization. Invasive blood pressure monitoring was achieved by cannulating the radial artery. The correct DLT position was confirmed again using a FOB. In group 0 , the F14 catheter was placed in the non-ventilated side lung of the patient for $2-3 \mathrm{~cm}$ after the bifurcation of the trachea and continued to be given oxygen in the low-medium flow rate of 1-4L / min. In group C, no special treatment was given to the patient after the single lung ventilation. In both groups, anesthesia induction and OLV were initiated and maintained using $100 \%$ oxygen. At the end of the surgery, the lung recruitment maneuver was given to the patient. When the operation was completed, the patients were discharged to the PACU or ICU.

\section{Measurements}

Both groups were simultaneously collected radial artery and jugular vein blood samples for blood gas analysis at immediate induction of anesthesia $\left(T_{1}\right)$, single lung ventilation 30min $\left(T_{2}\right), 1 \mathrm{~h}\left(\mathrm{~T}_{3}\right), 2 \mathrm{~h}\left(\mathrm{~T}_{4}\right)$. Cut off about $5 \mathrm{~cm}$ from the tumor size of about $3 \mathrm{~cm} \times 3 \mathrm{~cm} \times 3 \mathrm{~cm}$ lung tissue. The contents of SOD and MDA in lung tissue were determined by chemical colorimetry(The kit was provided by Nanjing Jiancheng Bioengineering Institute). HO-1 expression was detected by Western-blot(Kit by Abcam Technology Co., Ltd. and KPL Beijing West Mei Jie Technology Co., Ltd).

The same surgeons who were blinded to the lung collapse technique performed all surgical procedures. All of the data were recorded by another anesthesiologist who was unfamiliar with the lung collapse technique.

\section{Statistical analysis}

The data are expressed as the mean \pm standard deviation (SD) or as the number of patients. The statistical analyses were performed using a paired Student's t-test. The categorical variables were performed using the $\chi^{2}$-test. We performed the statistical analyses using SPSS version 21.0 (SPSS Inc. Chicago, IL, USA). A $P$-value $<0.05$ was considered statistically significant.

\section{Results}

A total of 60 patients were enrolled in this study, however, three patients were excluded from the data analysis. The final analyses included 28 patients in group 0 and 29 patients in group C (Fig. 1).

Patients' characteristics and surgical conditions, postoperative pulmonary complications were not different between two groups ( $P>0.05)$ (Table 1). 
Table 1 Patient characteristics

\begin{tabular}{|c|c|c|}
\hline Variable & Group $0(n=28)$ & Group C $(n=29)$ \\
\hline $\operatorname{Sex}(M / F)$ & $13 / 16$ & $13 / 15$ \\
\hline Age $\Downarrow$ years $\rrbracket$ & $63.42 \pm 5.34$ & $65.88 \pm 4.80$ \\
\hline Height $\triangle \mathrm{cm} \rrbracket$ & $162.16 \pm 6.90$ & $163.125 \pm 7.08$ \\
\hline Weight $\triangle \mathrm{kg} \rrbracket$ & $63.48 \pm 7.47$ & $64.34 \pm 5.46$ \\
\hline ASA class I/II & $13 / 15$ & $12 / 17$ \\
\hline Preoperative pulmonary function (normal / abnormal) & $21 / 10$ & $16 / 16$ \\
\hline Anesthesia time (min) & $254.03 \pm 58.69$ & $260.69 \pm 55.48$ \\
\hline Operation time (min) & $202.10 \pm 50.63$ & $210.01 \pm 48.56$ \\
\hline OLV time (min) & $172.71 \pm 51.15$ & $170.21 \pm 47.44$ \\
\hline Hospitalization time $(\mathrm{d})$ & $16.45 \pm 3.42$ & $18.65 \pm 3.22$ \\
\hline Postoperative hospital stay (d) & $9.03 \pm 2.11$ & $9.21 \pm 2.06$ \\
\hline Second intubation & 0 & 0 \\
\hline Chest tube indwelling time $(\mathrm{d})$ & $6.26 \pm 1.75$ & $6.34 \pm 1.73$ \\
\hline
\end{tabular}

The data are expressed as the mean \pm SD values or the number of patients. ASA, American Society of Anesthesiologists

The levels of arterial and venous blood gas analysis are given in table 2. The results of statistical analysis are presented in Fig. 2, from which we can see at $\mathrm{T}_{2-4}$, the $\mathrm{PaO}_{2}$ levels were significantly higher in group $O$ than in group C $(127 \pm 4.2$ vs $90 \pm 2.2,180 \pm 8$ vs $92 \pm 2.1,196 \pm 7.7$ vs $91 \pm 2.2)$. At $\mathrm{T}_{2-3}$, the $\mathrm{PaCO}_{2}$ levels were significantly lower in group 0 than in group C $(41.7 \pm 4.4$ vs $45.9 \pm 3.4,40.5 \pm 5.7$ vs $44.2 \pm 3.2)$. At $T_{2-3}$, the PvO2 levels were significantly higher in group 0 than in group $C(61 \pm 1.7$ vs $42 \pm 1.3,58 \pm 1.7$ vs 46 \pm 2.4$)$. At $\mathrm{T}_{2-4}$, the $\mathrm{PvCO}_{2}$ levels were significantly lower in group $\mathrm{O}$ than in group $\mathrm{C}$. ( $50 \pm 0.5$ vs $57 \pm 0.6$, $50 \pm 0.6$ vs $62 \pm 0.9,46 \pm 0.8$ vs $59 \pm 0.7)$.

Table 2 Blood gas analysis 


\begin{tabular}{llllll} 
Variable & Group & $\mathrm{T} 1$ & $\mathrm{~T} 2$ & $\mathrm{~T} 3$ & $\mathrm{~T} 4$ \\
\hline $\mathrm{PaO}_{2}(\mathrm{mmHg})$ & $\mathrm{O}(\mathrm{n}=28)$ & $337 \pm 10.4$ & $127 \pm 4.2^{*}$ & $180 \pm 8^{*}$ & $196 \pm 7.7^{\star}$ \\
\hline & $\mathrm{C}(\mathrm{n}=29)$ & $318 \pm 4.9$ & $90 \pm 2.2$ & $92 \pm 2.1$ & $91 \pm 2.2$ \\
\hline $\mathrm{PaCO}_{2}(\mathrm{mmHg})$ & $\mathrm{O}(\mathrm{n}=28)$ & $40.9 \pm 5.6$ & $41.7 \pm 4.4^{\star}$ & $40.5 \pm 5.7^{*}$ & $43.3 \pm 5.5$ \\
\hline & $\mathrm{C}(\mathrm{n}=29)$ & $35.6 \pm 1.4$ & $45.9 \pm 3.4$ & $44.2 \pm 3.2$ & $43.0 \pm 3.4$ \\
\hline $\mathrm{PvO}_{2}(\mathrm{mmHg})$ & $\mathrm{O}(\mathrm{n}=28)$ & $54 \pm 3.1$ & $61 \pm 1.7^{*}$ & $58 \pm 1.7^{*}$ & $58 \pm 1.6$ \\
\hline & $\mathrm{C}(\mathrm{n}=29)$ & $53 \pm 2.7$ & $42 \pm 1.3$ & $46 \pm 2.4$ & $48 \pm 2.6$ \\
\hline $\mathrm{PvCO}_{2}(\mathrm{mmHg})$ & $\mathrm{O}(\mathrm{n}=28)$ & $47 \pm 1.1$ & $50 \pm 0.5^{\star}$ & $50 \pm 0.6^{*}$ & $46 \pm 0.8^{\star}$ \\
\hline & $\mathrm{C}(\mathrm{n}=29)$ & $51 \pm 0.9$ & $57 \pm 0.6$ & $62 \pm 0.9$ & $59 \pm 0.7$
\end{tabular}

The data are expressed as the mean \pm SD values. ${ }^{*} P<0.05$ compared with group $C$

The levels of SOD, MDA and the expression levels of HO-1in the lung tissue are given in table 3 . The results of statistical analysis and the image of western-blotting are presented in Fig. 3, from which we can see that the levels of MDA were lower in group 0 than in group $C(8.09 \pm 3.30$ vs $17.39 \pm 8.40)$; however, the $\mathrm{HO}-1$ expression levels were higher in group 0 than in group $\mathrm{C}(0.76 \pm 0.49$ vs $0.21 \pm 0.15)$ (table3)

Table 3 MDA, SOD levels and expression of HO-1

\begin{tabular}{|c|c|c|}
\hline Variable & Group O\n=28\ & Group C『n=29》 \\
\hline SOD (U/mgprot) & $13.46 \pm 2.97$ & $17.69 \pm 1.65$ \\
\hline MDA (nmol/mgprot) & $8.09 \pm 1.30 \star$ & $17.39 \pm 2.40$ \\
\hline HO-1 expression & $0.76 \pm 0.09 *$ & $0.21 \pm 0.05$ \\
\hline
\end{tabular}

The data are expressed as the mean \pm SD values. ${ }^{*} P<0.05$ compared with group $C$

\section{Discussion}

Temporary, one lung ventilation (OLV) is an anesthetic procedure performed to facilitate thoracic surgeries. While this procedure is medically necessary, there is ample evidence to suggest that OLV procedures can lead to lung injury through various mechanisms. These include hypoxia, ischemia/reperfusion, mechanical injury in the collapsed lung, hyperperfusion of the ventilated lung (due in part to its gravitationally dependent positioning during surgery and in part to pulmonary shunting and over distension of alveoli), and oxidative injury from high $\mathrm{FiO}_{2}[1,10]$, which are causes of ALI after surgery. Protective ventilation is essential to reduce lung injury. Therefore, protective ventilation (including tidal volume, respiratory frequency and PEEP) was applied before OLV and for the ventilated lung during OLV to reduce the influence of non-research factors on the observed factors. 
As for collapsed lung, protective OLV results in reduced ALI, critical care admissions, and hospital length of stay[11]. Continuous Positive Airway Pressure(CPAP) should be considered as one of the protective ventilation during OLV for collapsed lung to avoid dense atelectasis and minimize the shunt fraction. The incomplete lung collapse associated with CPAP is compatible with many chest wall and peripheral lung procedures. Even during thoracoscopic procedures, low-level CPAP of $2 \mathrm{~cm} \mathrm{H}_{2} \mathrm{O}$ has been shown to be feasible without impairing surgical exposure[5]. This approach has been shown to reduce hypoxic pulmonary vasoconstriction(HPV) and attenuate inflammatory cytokine release during clinical esophagectomy[12]. The impact of recruitment maneuvers on the alveolar-capillary membrane may be minimized by the use of slow airway pressure increases[13] and cycling maneuvers[14]. The use of lower $\mathrm{FiO}_{2}$ during recruitment maneuvers may reduce the creation of reactive oxygen species, but this has not been studied in the OLV setting[15]. Therefore, we applied the continuous administration of low-medium flow oxygen (1-4L/min) and maintain the pressure between $1-2 \mathrm{~cm} \mathrm{H}_{2} \mathrm{O}$ for $\mathrm{NVL}$ to simulate CPAP in our study. Our result showed that compared with group $\mathrm{C}$, the $\mathrm{PaO}_{2}$ levels increased at $\mathrm{T}_{2-4}$ in group $\mathrm{O}$, the $\mathrm{PaCO}_{2}$ levels decreased at $\mathrm{T}_{2,3}$, the $\mathrm{PvO}_{2}$ levels increased at $\mathrm{T}_{2,3}$, the $\mathrm{PvCO}_{2}$ levels decreased at $\mathrm{T}_{2-4}$, implying that the continuous administration of low-medium flow oxygen for NVL during OLV may improve partial pressure of oxygen $\left(\mathrm{PO}_{2}\right)$ and lower partial pressure of carbon dioxide $\left(\mathrm{PCO}_{2}\right)$ to improve abnormal ventilation / blood flow ratio in NVL and thus play a role in lung protection.

Chow CW et al reported that lung parenchyma is one of the largest accumulations of neutrophils, monocytes and macrophages, and is also an important organ for oxidative stress reaction[16]. (After Ipsilateral lung recover ventilation and, but a large number of oxygen molecules into the tissues release large amounts of oxygen free radicals and cause tissue damage). Once ipsilateral lung ventilation recovers and low blood perfusion lung/hypoxia improves, excessive oxygen molecules in the tissues will release large amounts of oxygen free radicals and cause tissue damage. SOD is an oxygen free radical scavenger, widely presenting in the lung and having a protective effect on lung injury[17]. MDA is the final product of lipid peroxidation, directly reflecting the level of free radicals. The MDA content level is an important sign of tissue damage[18]. HO-1, the heme-degrading enzyme, has shown anti-inflammatory effects in several models of pulmonary diseases. HO-1 attenuates lung edema by inhibiting the oxidation of lipid membranes and scavenging free radicals, the expression level of which increases when hypoxia, ischemia or other noxious stimulations occurs[19]. Almolki A et al confirmed that upregulation of the $\mathrm{HO}$ pathway has a significant protective effect against oxidative stress response[20]. The result showed that The MDA levels in the lung tissue were lower in group 0 than in group C; however, the HO-1 expression levels were higher in group $O$ than in group $C$, which implied that the administration of continuous lowmedium flow oxygen for NVL during OLV may inhibit lung tissue oxidative stress response, resulting in the role of lung protection. The possible mechanism is as follows: 1. Improvement of hypoxia can directly affect the SOD content: Studies have shown that hypoxia can directly inhibit the generation of endogenous SOD. Improving the hypoxia can increase the content of SOD, accelerate the elimination of oxygen free radicals to inhibit oxidative stress[21-22]. The results of this study showed no significant difference in lung tissue SOD content between the two groups of patients. It may be related to the smaller sample size, also related to the decrease of antioxidant ability in patients with cancer. Misthos $\mathrm{P}$ et al 
founded that patients with cancer have a higher oxidative burden and may have less antioxidant capacity[8]. 2. Improvement of changes in the pulmonary circulation (HPV) caused by hypoxia in NVL can reduce the formation of oxygen free radicals: The existing research has shown that HPV is directly related to the generation of oxygen free radicals and oxidative stress response[23]. As HPV causes relatively insufficient perfusion in lung tissue, it directly causes the generation of oxygen free radicals and the destruction of vascular structure, and indirectly causes the release of various vasoactive factors and inflammatory factors, resulting in the occurrence of oxidative stress response. Cheng YD et al founded that during OLV in NVL, acute HPV is produced with increased systemic MDA, suggesting an increased oxidative stress response[6]. Therefore, the administration of continuous low-medium flow oxygen for NVL during OLV can improve the acute HPV occurrence in NVL in order to inhibit oxidative stress. 3. Ischemia-reperfusion injury: Acute HPV during OLV causes increased pressure on the pulmonary circulation, decreased blood flow and oxygen supply in NVL tissue, abnormalities in the production or inactivation of vasoactive substances in the tissue, which may cause or exacerbate pulmonary vascular endothelial cell damage such as cell swelling, interstitial edema or vascular wall permeability changes. Liu $\mathrm{R}$ et al have confirmed such pathophysiological process on rat-OLV model[24]. After reoxygenation, while hypoperfusion and hypoxia improve in NVL, a large number of oxygen molecules influx into the tissue, releasing a large number of oxygen free radicals, thus causing oxidative stress response, and then lung tissue damage. After clinically relevant durations of lung collapse in rat models[25] and patients, as reventilation after a period of clinical OLV substantially increased exhaled hydrogen peroxide concentrations in breath condensate, myeloperoxidase levels in bronchoalveolar lavage samples, and systemic markers of oxidative stress[8-9,26]. So the administration of continuous low-medium flow oxygen for NVL during OLV may inhibit the occurrence of ischemia-reperfusion injury to a certain extent. 4. Upregulation of HO-1 gene expression: Studies have shown that HO-1, one of the most important endogenous protective protein in the body, has a variety of physiological regulatory functions, such as anti-oxidation, anti-inflammatory response, anti-necrosis and cell protection[27]. HO-1 and its metabolites have strong antioxidant effects[28]. Our results showed that the expression of HO-1 was up-regulated in the lung tissues of the patients with continuous low-medium flow oxygen supply for the NVL during OLV compared with that in the control group, indicating that $\mathrm{HO}-1$ could play a role in lung protection.

\section{Conclusion}

The administration of continuous low-medium flow oxygen for NVL during OLV has shown the effect of pulmonary protection. The possible mechanism is related with the inhibition of the oxidative stress response in lung tissue.

\section{Abbreviations}

ALI: Acute lung injury; CPAP: Continuous Positive Airway Pressure; DLT: Double-lumen tube; ECG:

Electrocardiography; FEV1: forced expiratory volume in one second; FOB: Fibreoptic bronchoscopy; H0-1: Heme oxygenase-1; HPV: Hypoxic pulmonary vasoconstriction; HR: Heart rates; ICU: Intensive care unit; 
MAP: Mean arterial blood pressures; MDA: Malondialdehyde; NIBP: Non-invasive blood pressure; NVL: Non-ventilated lung; OLV: One-lung ventilation; PaCO2: Arterial carbon dioxide partial pressure; PACU: Post-anesthetic care unit; PaO2: Arterial oxygen partial pressure; PEEP: Positive end expiratory pressure; PvCO2: Venous carbon dioxide partial pressure; PvO2: Venous oxygen partial pressure; ROS: Reactive oxygen species; SOD: Superoxide dismutase; TAS: Total antioxidant status; Vt: Tidal volume.

\section{Declarations}

\section{- Ethics approval and consent to participate}

This study was approved by the the ethical standards of the Medical Ethics Committee of Zhongnan Hospital of Wuhan University (Clinical Trial Registry number, 2016020), and the patients provided written informed consent.

\section{-Consent for publication}

Not applicable.

\section{-Availability of data and materials}

The datasets generated during the current study are not publicly available due to the authors do not wish to share their data, because the patients who participated in this study did not agree to share their individual data.

\section{-Competing interests}

The authors declare that they have no competing conflicts of interest.

\section{-Funding}

There was no financial support.

\section{-Acknowledgements}

The authors would like to thank our subjects for their participation in this study.

\section{Authors' contributions}

TJ Wu carried out the experiments and prepared the manuscript. J Zhan, JJ Ke and ZZ Zhang participated in the design of the experiments and carried out the experiments. YL Wang designed the study and prepared the manuscript. All authors have read and approved the manuscript. 


\section{References}

1. Lohser J, Slinger P. (2015). Lung injury after one-lung ventilation. Anesthesia Analgesia, 121(2), 30218. doi:10.1186/s40064-016-2867-0.

2. Tsukada K, Miyazaki T, Katoh H, et al. (2004). Interferon- $y$ and granulocyte colony-stimulating factor in bronchoalveolar lavage fluid after oesophagectomy. Digestive \& Liver Disease Official Journal of the Italian Society of Gastroenterology \& the Italian Association for the Study of the Liver, 36(9), 572-576. doi:10.1016/j.dld.2004.05.006.

3. Cree RTJ, Warnell I, Staunton M, et al. (2004). Alveolar and plasma concentrations of interleukin-8 and vascular endothelial growth factor following oesophagectomy. Anaesthesia, 59(9), 86771.doi:10.1111/j.1365-2044.2004.03672.x.

4. Tsukada K, Hasegawa T, Miyazaki T, et al. (2001). Predictive value of interleukin-8 and granulocyte elastase in pulmonary complication after esophagectomy. Am J Surg, 181(2), 167-71. doi:10.1016/S0002-9610(00)00558-4.

5. Licker $M$, Fauconnet $P$, Villiger $Y$, et al. (2009). Acute lung injury and outcomes after thoracic surgery. Current Opinion in Anaesthesiology, 22(1), 61-7.doi:10.1097/AC0.0b013e32831b466c.

6. Cheng YD, Gao Y, Zhang H, et al. (2014). Effects of olv preconditioning and postconditioning on lung injury in thoracotomy. Asian J Surg, 37(2), 80-5. doi:10.1016/j.asjsur.2013.09.003.

7. Lima Trajano ET, Sternberg C, Caetano et al. (2011). Endotoxin-induced acute lung injury is dependent upon oxidative response. Inhalation Toxicol, 23(14), 918-26. doi:10.3109/08958378.2011.625994.

8. Misthos P, Katsaragakis S, Milingos N, et al. (2005). Postresectional pulmonary oxidative stress in lung cancer patients. the role of one-lung ventilation. Eur J Cardiothorac Surg, 27(3), 379-83.

doi:10.1016/j.ejcts.2004.12.023.

9. Cheng YJ, Chan KC, Chien CT, et al. (2006). Oxidative stress during 1-lung ventilation. Journal of Thoracic Cardiovascular Surgery, 132(3), 513-8. doi:10.1016/j.jtcvs.2006.03.060.

10. Hayes M, Curley GF, Masterson C, et al. (2014). Pulmonary overexpression of inhibitor KBa decreases the severity of ventilator-induced lung injury in a rat model. Br J Anaesth, 113(6), 1046-54. doi:10.1093/bja/aeu225.

11. El-Tahan MR, Ghoneimy E, Regal YF MA et al. (2011). Comparative study of the non-dependent continuous positive pressure ventilation and high-frequency positive-pressure ventilation during one-lung ventilation for video-assisted thoracoscopic surgery. Interact CardioVasc Thorac Surg, 12(6), 899-902. doi:10.1510/icvts.2010.264911.

12. Verhage RJJ, Boone J, Rijkers GT, et al. (2014). Reduced local immune response with continuous positive airway pressure during one-lung ventilation for oesophagectomy. $\mathrm{Br} J$ Anaesth, 112(5), 920-8. doi:10.1093/bja/aet476.

13. Silva PL, Moraes L, Santos RS, et al. (2011). Impact of pressure profile and duration of recruitment maneuvers on morphofunctional and biochemical variables in experimental lung injury*. Crit Care Med, 39(5), 1074-81. doi:10.1097/ccm.0b013e318206d69a. 
14. Marini JJ.. (2011). Recruitment by sustained inflation: time for a change. Intensive Care Med, 37(10), 1572-4. doi:10.1007/s00134-011-2329-7.

15. Douzinas EE, Kollias S, Tiniakos D, et al. (2004). Hypoxemic reperfusion after 120 min of intestinal ischemia attenuates the histopathologic and inflammatory response *. Crit Care Med, 32(11), 2279-83. doi:10.1097/01.ccm.0000145582.03345.c8.

16. Chow C. (2003). Oxidative stress and acute lung injury. American Journal of Respiratory Cell Molecular Biology, 29(4), 427. doi:10.1165/rcmb.F278.

17. Devasagayam TP, Tilak JC, Boloor KK, et al. (2004). Free radicals and antioxidants in human health: current status and future prospects. J Assoc Physicians India, 52(794804), 794.

18. Pfeifer PM, Mccay PB.. (1971). Reduced triphosphopyridine nucleotide oxidase-catalyzed alterations of membrane phospholipids. v. use of erythrocytes to demonstrate enzyme-dependent production of a component with the properties of a free radical. J Biol Chem, 246(21), 6401.

19. Durante W. (2011). Protective role of heme oxygenase-1 against inflammation in atherosclerosis. Front Biosci, 16(3), 2372-88. doi:10.2741/3860.

20. Almolki A, Taillé C, Martin GF, et al. (2004). Heme oxygenase attenuates allergen-induced airway inflammation and hyperreactivity in guinea pigs. American Journal of Physiology Lung Cellular Molecular Physiology, 287(1), 26-34. doi:10.1152/ajplung.00237.2003.

21.

(2014). Oxymatrine prevents hypoxia- and monocrotaline-induced pulmonary hypertension in rats. Free Radical Biology and Medicine, 69, 198-207. doi:10.1016/j.freeradbiomed.2014.01.013.

22. Araneda OF, Tuesta M. (2012). Lung oxidative damage by hypoxia. Oxidative Medicine Cellular Longevity, 2012, 1-18. doi:10.1155/2012/856918.

23. Ariyaratnam P, Loubani M, Morice AH. (2013). Hypoxic pulmonary vasoconstriction in humans. Biomed Research International, 2013(2, part 2), 623684. doi:10.1155/2013/623684.

24. Liu R, Ishibe Y, Ueda M. (2000). Isoflurane-sevoflurane adminstration before ischemia attenuates ischemia-reperfusion-induced injury in isolated rat lungs. Anesthesiology, 92(3), 833. doi:10.1097/00000542-200003000-00027.

25. Tekinbas C, Ulusoy H, Yulug E, et al. (2007). One-lung ventilation: for how long? Journal of Thoracic Cardiovascular Surgery, 134(2), 405-10. doi:10.1016/j.jtcvs.2007.05.003.

26. Lases, Edmée C, Duurkens VAM, Gerritsen WBM, et al. (2000). Oxidative stress after lung resection therapy. Chest, 117(4), 999-1003. doi:10.1378/chest.117.4.999.

Shen 27 SongS, Tang $X Y$, et al. Sinomenine pretreatment attenuates cold ischemia/reperfusion injury in rats: the role of heme oxygenase-1. Int Immunopharmacol. 2010;10(6):0-684.

doi:10.1016/j.intimp.2010.03.011.

28. Arimori YY. (2010). Role of heme oxygenase-1 in protection of the kidney after hemorrhagic shock. Int J Mol Med, 26(1), 27-32. doi:10.3892/ijmm_00000430.

\section{Figures}




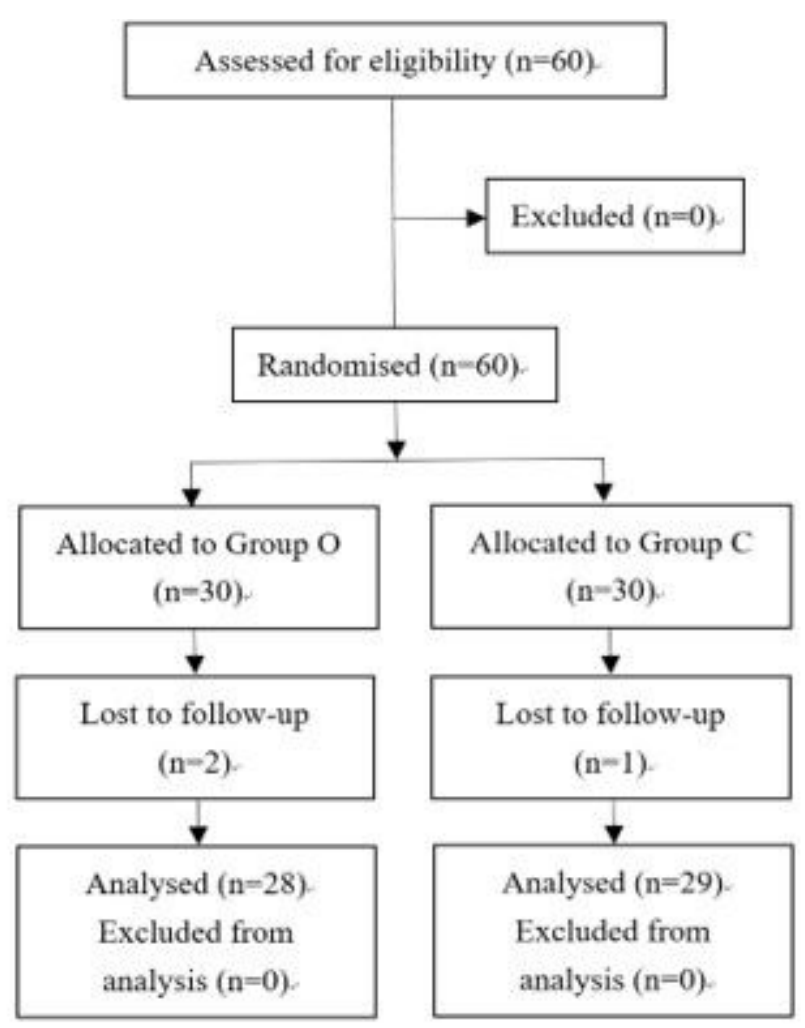

Figure 1

CONSORT flow diagram
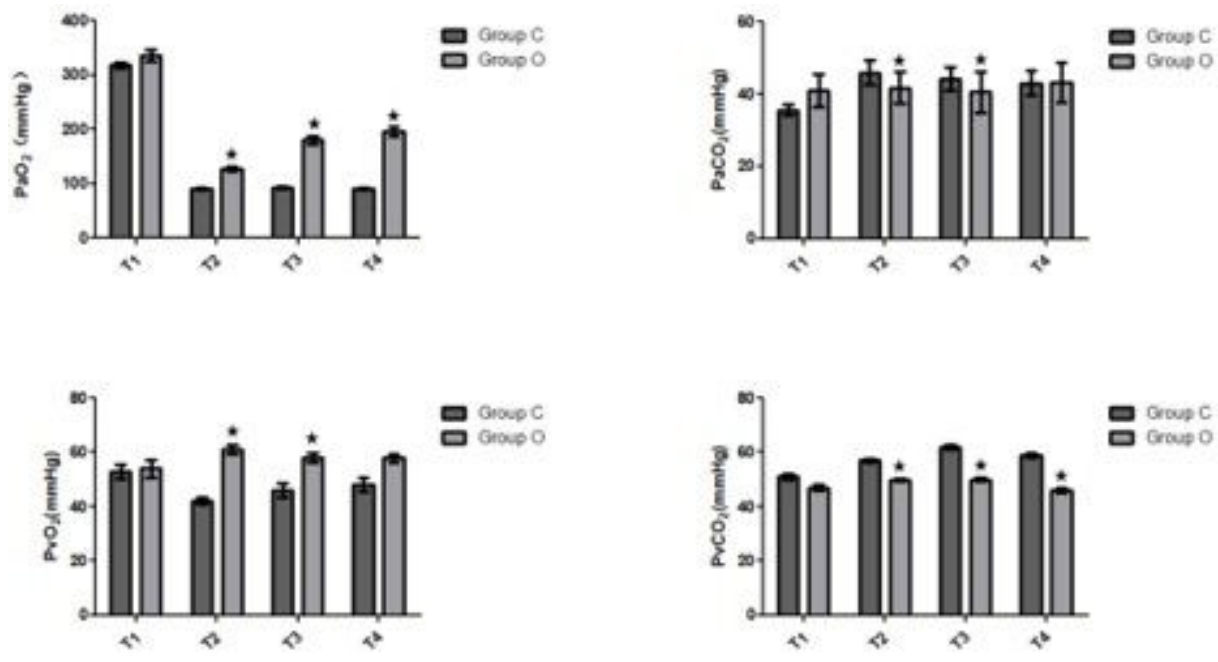

Figure 2

Levels of arterial and venous blood gas analysis in each group at different times: T1, T2, T3 and T4. *P< 0.05 compared with group $C$. 


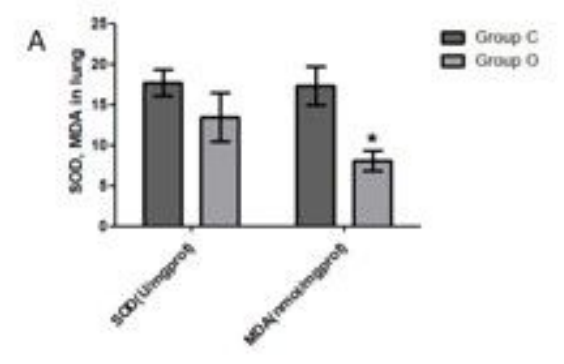

B

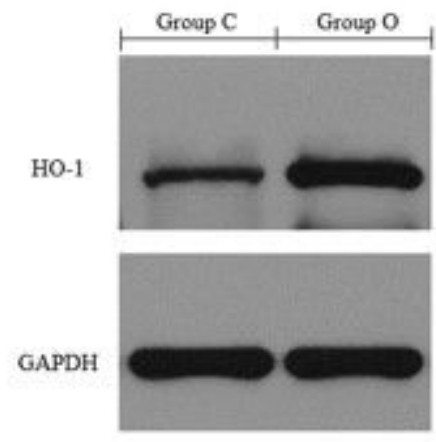

C

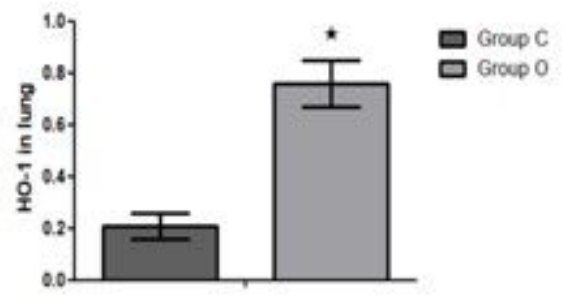

Figure 3

Histograms of SOD, MDA and HO-1 in lung tissues of two groups. ${ }^{*} \mathrm{P}<0.05$ compared with group $\mathrm{C}$. 